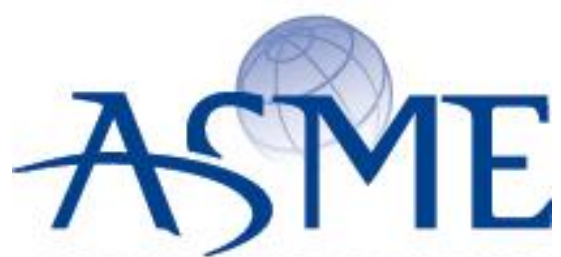

SETTING THE STANDARD

\section{American Society of Mechanical Engineers}

ASME Accepted Manuscript Repository

Institutional Repository Cover Sheet

DEHONG

HOU

First

Last

A NEW SURFACE TOPOGRAPHY-BASED METHOD TO QUANTIFY AXIAL ERROR OF HIGH SPEED

ASME Paper Title: MILLING CUTTERS

Authors: $\quad$ CHEN W, LU L, ZIE W, HUO D, YANG K

ASME Journal Title: JOURNAL OF MANUFACTURING SCIENCE AND ENGINEERING

Volume/Issue 140(11)

Date of Publication (VOR* Online) 31-08-2018

ASME Digital Collection URL: https://doi.org/10.1115/1.4041180

DOI: $\quad 10.1115 / 1.4041180$

*VOR (version of record) 


\title{
A new surface topography-based method to quantify axial error of high speed milling cutters
}

\author{
Wanqun Chen ${ }^{1,2}$, Lei Lu ${ }^{1}$, WenKun Xie ${ }^{1}$, Dehong Huo ${ }^{2 *}$, Kai Yang ${ }^{3}$ \\ 1.School of Mechatronics Engineering, Harbin Institute of Technology, Harbin 150001, P. R. China \\ 2.Mechanical Engineering, School of Engineering, Newcastle University, Newcastle upon Tyne, NE1 \\ 7RU, UK \\ 3. Army Aviation Institute, Beijing 101123, P. R. China
}

*Corresponding author: D. Huo, Tel: +44 (0) 191208 6230,E-mail:_dehong.huo@newcastle.ac.uk

\begin{abstract}
Cutting tool rotation errors have significant influence on the machined surface quality, especially in micro milling. Precision metrology instruments are usually needed to measure the rotation error accurately. However, it is difficult to directly measure the axial error of micro milling tools due to the small diameters and ultra-high rotational speed. To predict the axial error of high speed milling tools in the actual machining conditions and avoid the use of expensive metrology instruments, a novel method is proposed in this paper to quantify the cutting tool error in the axial direction based on the tool marks generated on the machined surface. A numerical model is established to simulate the surface topography generation, and the relationship between tool marks and the cutting tool axial error is then investigated. The tool axial errors at different rotational speeds can be detected by the proposed method. The accuracy and reliability of the proposed method are verified by machining experiments.
\end{abstract}

Keywords: axial error; tool runout; surface prediction; milling; tool marks

\section{Introduction}

Rotation error, a key evaluation index for precision rotational equipment $[1,2]$, has significant influence on tool life, geometrical/dimensional accuracy, and surface roughness of machined surface [3-5]. In high precision machining, cutter rotation errors can be controlled in micron or even sub-micron scale, and hence can be neglected in conventional machining. But for micro milling, cutting tool rotation error has to be taken into account, as it has a significant effect on machining process and the final surface quality acquisition [6,7]. Thus, it is imperative to measure tool rotation errors and evaluate the performance of the rotational cutter system in micro milling.

In micro milling, cutting tool errors are mainly introduced by the spindle and tool manufacturing and installation error, such as the deviation distance between the tool center to the spindle center. the total errors can be recognized as radial runout and axial runout. Radial runout is mainly caused by the eccentricity of tool and spindle rotational components. Differently, axial runout is formed due to the angular misalignment of tool geometric and rotational axis as shown in Fig.1a). Fig.1 b) and c) show the cutter status without and with the radial runout, Fig.1d) and e) illustrate the cutter status without and with the axial runout. It can be clearly seen in Fig. 1 e) that axial runout can lead to the drift of the tip of the tool (or shaft) from the base. Detection of tool runout enables accurate prediction of the surface 
roughness and surface topography, as well as the selection of the machining parameters in milling process. However, up to date, it remains to be difficult to detect the cutter errors in high speed milling.

a)

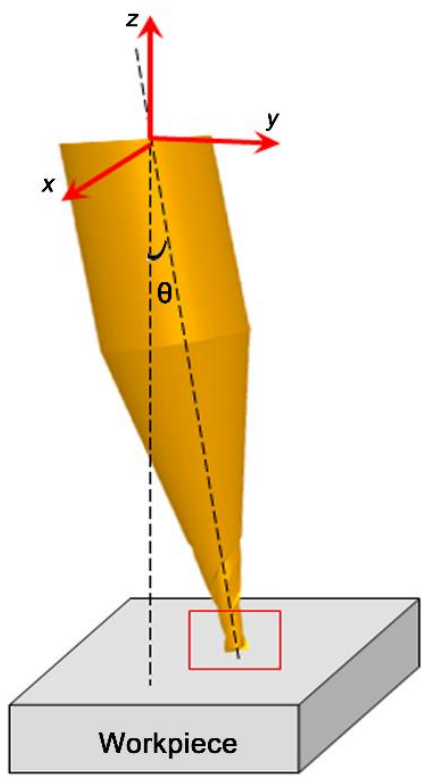

b)

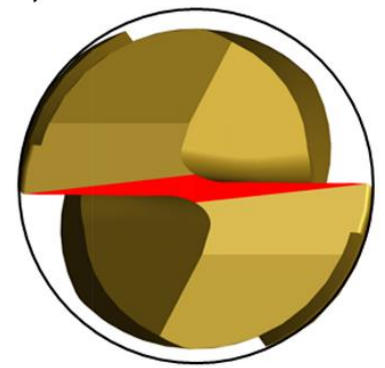

d)

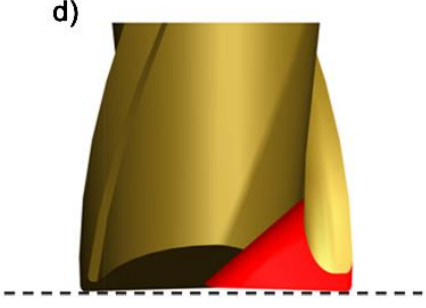

c)

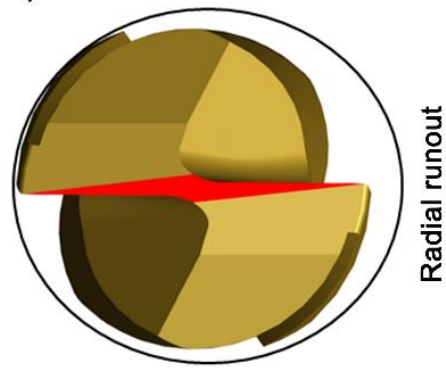

e)

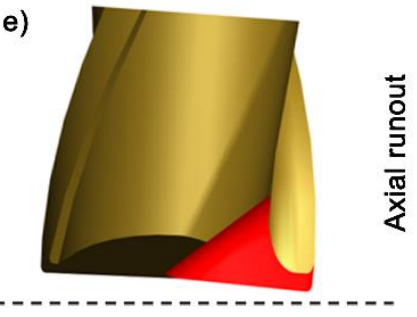

Fig.1 Cutter error in micro milling. a) schematic of runout in milling process. b) no radial runout; c) radial runout; d) no axial runout; e) axial runout

A precision gauge pin is usually used to replace cutting tools when measuring spindle runout. Due to the cutting tool centering and unbalance errors, this method only evaluates spindle runout but not the actual cutter system, hence it will result in errors in predicting machined surface performance. Furthermore, capacitive sensors or eddy current sensors typically used for the measurement of the spindle runout will also introduce errors when measuring miniature spindle systems, due to the nonlinear charge between a flat plate (sensing area) and a curved surface (measuring target area), in which the effective sensing area being larger than the measuring target area.

At present, two types of methods, including direct and indirect ones, are employed to measure the tool runout. The direct measurement methods consist of static and dynamic measurement. For the static measurement, to specify the magnitude and phase angle of the runout, a measurement probe is first mounted, directly contacting with the reference pin. As shown in Fig.2a), the probe of a dial indicator is kept contact with the tip, and the contact point is served as the reference point. Then the tool tip is manually rotated by $60^{\circ}$ angular increments (to encompass one full rotation) and the deviation from the reference value at each increment is timely recorded. The maximum deviation with respect to the reference point can be specified as tool run-out. This type of measurement method can only be used for quasi-static state (the spindle rotation speed is less than $60 \mathrm{rpm}$ ), due to the low response speed of the test equipment [8]. Differently, for the dynamic measurement, high resolution displacement sensors, e.g. capacitive sensors [9] and laser displacement sensor, should be applied to test the spindle mounting with a reference pin, as shown in Fig.2b). While, for micro milling, the maximum spindle rotation speed can be over 100,000rpm. Owing to the 
high rotation speed-induced airflow, vibration, and difficulties in sensor fixturing, the runout measurement in micro milling remains to be extremely challenging. By utilizing the curved-edge diffraction based sensor, Lee et al. [10] proposed a novel but simple optical monitor method to measure the runout of miniature spindle.

As for the indirect method, the phenomenon in the machining process, e.g. cutting forces and tool marks, are adopted to predict the spindle runout. As shown in Fig.2c), the cutting marks are circular, and their diameters are related to the radial error of the cutter system. Thus, Nakkiew et al. [11] introduced one tool marks-based method to measure the spindle runout at very high speed. It can be also noted in Fig.2 b) that the model-based approaches through measuring cutting forces are also proposed to identify the tool runout [12-14]. Using this kind of approach, the prediction of the tool runout could be not limited by the spindle rotation speed, while expensive special metrology instruments are not necessary. More importantly, the tool effect could be considered in the indirect measurement methods. However, the accuracy of prediction value of tool runout obtained in this method is difficult to be ensured. Moreover, the predicted tool runout is usually not time-resolved and angle-resolved.

a)

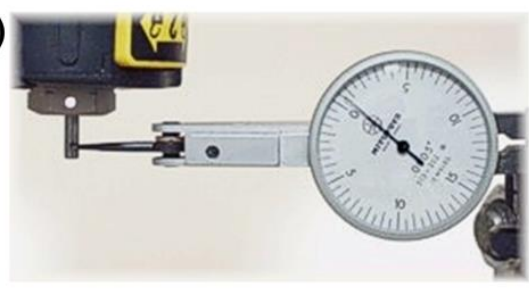

Static measurement

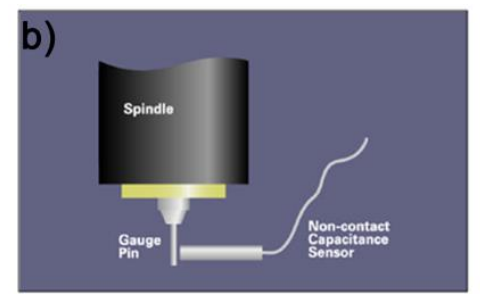

Dynamic measurement

Direct measurement method

c)

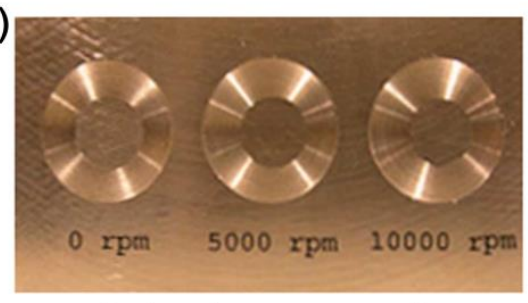

Tool marks measurement

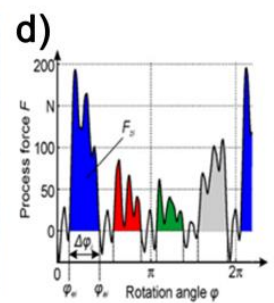

Cutting force measurement

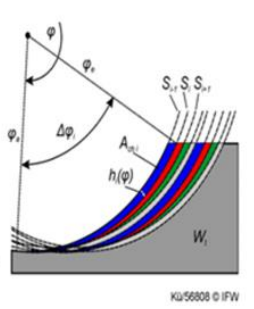

$$
\text { ent }
$$

Indirect measurement method

Fig.2 Tool runout measurements. a) static measurement; b) dynamic measurement; c) tool marks measurement [10]; d) cutting force measurement [12]

Most of the previous work was focused on the radial runout through either direct or indirect measurement method, while little attention has been paid on the axial runout. In our previous study [7], we found that the axial runout has significant influence on the surface generation and roughness. Thus, the measurement of the axial runout plays an important role in the prediction of the surface topography and the selection of machining parameters. However, due to the complex end face shape and small diameter of the cutter, the axial runout direct measurement is not practical. In this study, a novel axial runout prediction model based on machined surface topography is proposed to identify the axial runout of the cutter system.

\section{Axial runout prediction method based on the machined surface topography detection}


a)

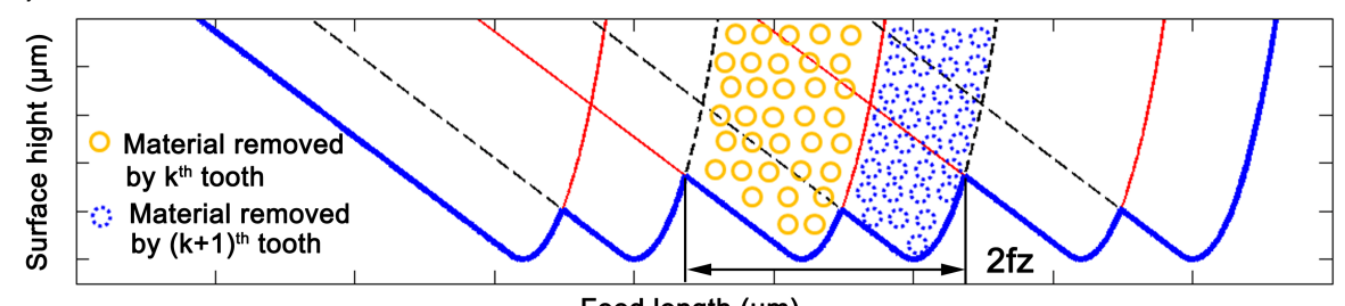

Feed length $(\mu \mathrm{m})$

b)

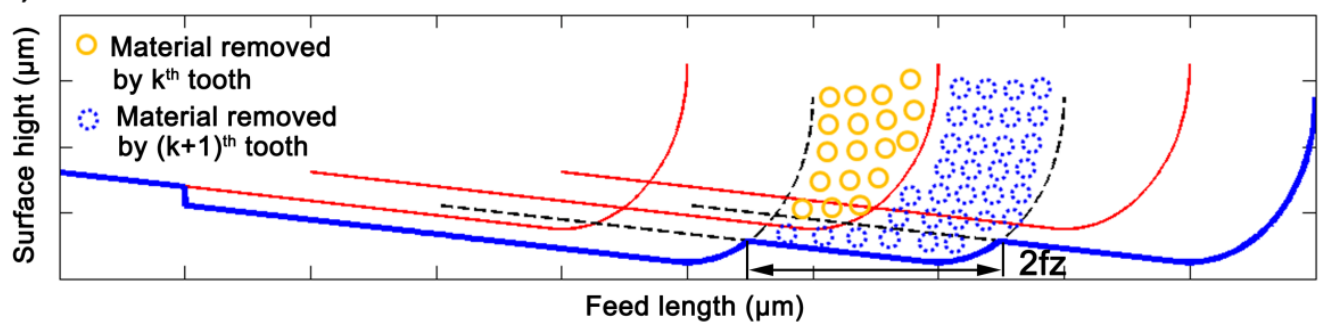

Fig.3 The tool path diagram considering runout. a) radial runout, b) axial runout

Figure 3 illustrates the typical cutter trajectories with radial and axial runout, as shown in Fig.3a). It is can be noted that the radial tool runout changes the uncut chip thickness obviously, and hence affects the cutting force significantly [15-17]. While, the axial tool runout mainly contributes to the tool mark of the machined surface, as shown in Fig.3b), and affects the machined surface topography significantly. It can be found that when the axial runout is larger than a specific value, the tool mark left by $k^{\text {th }}$ tooth will be removed by the following tooth, thus the distance between the two adjacent tool marks is changed to be twice of the feed per tooth rather than the feed per tooth as shown in Fig.3a).

For above reasons, the paper first investigates the quantitative relationship between the axial runout and machined surface topography. And on this basis, a novel axial runout prediction model based on the machined surface topography is proposed to identify the axial runout of the cutter system.

\subsection{Relationship between the axial runout and machined surface topography generation}
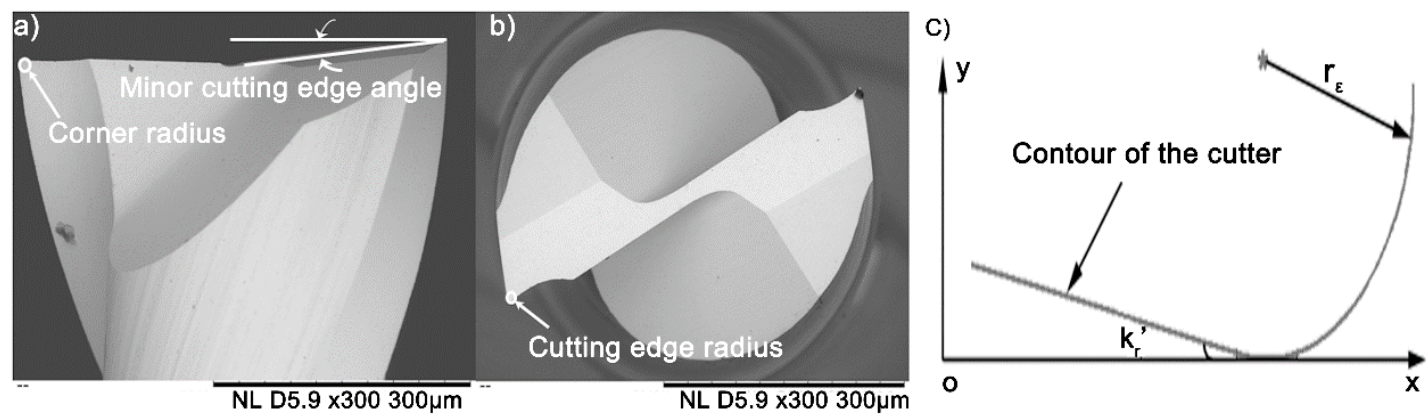

Fig.4 Tool geometry. a) side view; b) top view; c) end cutter edge profile.

Before the cutting experiments, the micro end mills were measured by SEM and AFM to obtain the cutter geometry parameters. The rake angle is measured in analysis software ImageJ. Besides, the cutter corner radius is measured by an AFM, and the 
corner radius is further determined by using the least squares fit method. Fig.4 a) and b) show the side and top views of the micro cutting tool and the detailed geometrical parameters of the micro cutting tool are listed in Table 1.

Table 1 Parameters of the micro cutting tool

\begin{tabular}{ll}
\hline Parameters & Value \\
\hline Cutting diameter, $D$ & $0.5 \mathrm{~mm}$ \\
\hline Number of flutes & 2 \\
\hline Cutter edge radius, $r_{e}$ & $3 \mu \mathrm{m}$ \\
\hline Rake angle, $\boldsymbol{k}_{\boldsymbol{r}}^{\prime}$ & $10^{\circ}$ \\
\hline Corner radius, $r_{\varepsilon}$ & $5 \mu \mathrm{m}$ \\
\hline
\end{tabular}

Fig. 4 c) shows the cutter edge profile for an end mill. It can be clearly observed that the cutter edge profile consists of a linear segment and curved segment. The linear segment is inclined with a rake angle, $k_{r}^{\prime}$.Owing to the existence of the concavity angle, the friction between the tool and workpiece tends to be lower. Moreover, the concavity angle could affect the shape of the floor surface profile. The curved segment (namely, the radius of the tool tip) dominates the surface finish of the machined workpiece in the micro-end milling process. Therefore, it is the most significant parameter of this model. Thus, the cutter profile $(x, y)$, which represents the end cutter edge and the corner radius of the tool, can be expressed as:

$y=\left\{\begin{array}{lc}\sqrt{r_{\varepsilon}^{2}-x^{2}} ; & r_{\varepsilon} \geq x>-r_{\varepsilon} \sin \left(k_{r}^{\prime}\right) \\ r_{\varepsilon} \cos \left(k_{r}^{\prime}\right)+\left(x+r_{\varepsilon} \sin \left(k_{r}^{\prime}\right)\right) \tan \left(k_{r}^{\prime}\right) ; & x \leq-r_{\varepsilon} \sin \left(k_{r}^{\prime}\right)\end{array}\right.$

where $r_{\varepsilon}$ and $k_{r}^{\prime}$ denote the tool corner radius and rake angle, respectively.

The ideal surface roughness (peak to valley) without considering the effect of the tool runout (as shown in Fig.5a)) can be expressed as

$R_{\operatorname{Imax}}=r_{\varepsilon}\left(1-\cos k_{r}^{\prime}\right)+f_{z} \sin k_{r}^{\prime}\left(\cos k_{r}^{\prime}-\sin k_{r}^{\prime} \sqrt{\frac{2 r_{\varepsilon}}{f_{z} \sin k_{r}^{\prime}}-1}\right)$

where, $f_{z}$ is feed per tooth.

With the movement of the cutter along the feed direction, the machined surface is gradually generated by the tool circular arc edge and the end cutter edge. Owing to the effect of the tool axial runout, two typical cases occur, which could be illustrated as follows:

Case 1: as shown in Fig.5b), the machined surface is generated by teeth, and the surface roughness (peak to valley) could be expressed by:

$$
\begin{aligned}
& R_{\text {Amax } 1}=\left(r_{\varepsilon}-\sqrt{-\left(f_{z}+2 r_{\text {axial }} \cot \left(k_{r}^{\prime}\right)\right)\left(f_{z}+2 r_{\text {axial }} \cot \left(k_{r}^{\prime}\right)-2 r_{\text {axial }} \csc \left(k_{r}^{\prime}\right)\right)}+\right. \\
& \left.\cot \left(k_{r}^{\prime}\right)\left(f_{z}+\left(r_{\varepsilon}+2 r_{\text {axial }}\right) \cot \left(k_{r}^{\prime}\right)-r_{\varepsilon} \csc \left(k_{r}^{\prime}\right)\right)\right)\left(\sin \left(k_{r}^{\prime}\right)\right)^{2}
\end{aligned}
$$


where, $r_{\text {axial }}$ refers to the magnitude of the axial tool runout. It can be found that the $R_{\text {Amax }}$ consists of the ideal roughness and the axial tool runout. The distance between the adjacent two tool mark generated on the machined surface is equal to the feed per tooth.

Case 2: as shown in Fig.5c), the mainly surface is generated by the trajectories of one tooth. The surface roughness (peak to valley) could be calculated by:

$R_{\text {Amax } 2}=r_{\varepsilon}\left(1-\cos k_{r}^{\prime}\right)+2 f_{z} \sin k_{r}^{\prime}\left(\cos k_{r}^{\prime}-\sin k_{r}^{\prime} \sqrt{\frac{r_{\varepsilon}}{f_{z} \sin k_{r}^{\prime}}-1}\right)$

In the milling process, the material removal is mainly performed by the second tooth. Moreover, the temporary tool marks generated by the second tooth is immediately removed by the first tooth. Thus, the second tooth does not contribute to the final surface generation. To summarize, the period of the tool marks is equal to twice of the feed per tooth, rather than approximately the feed per tooth in the first case.

a)

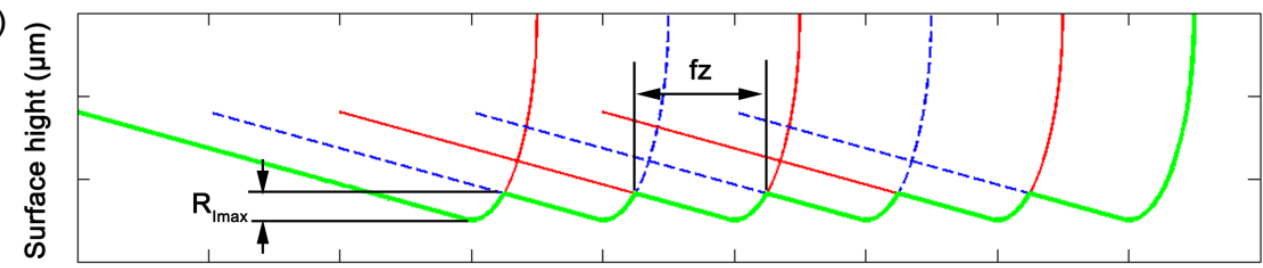

Feed length $(\mu \mathrm{m})$

b)

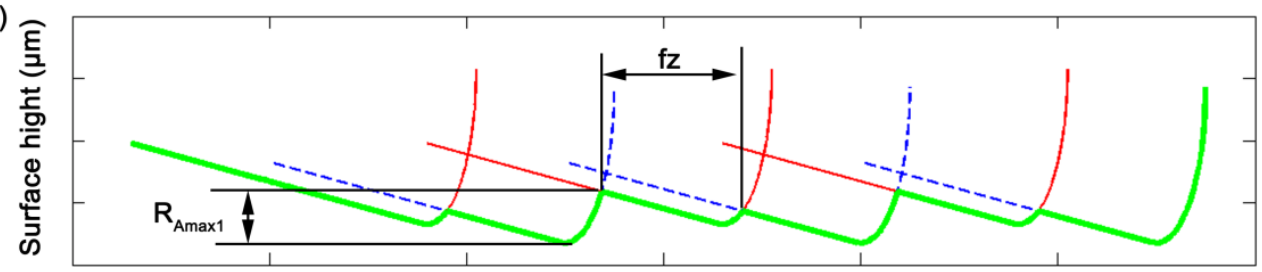

Feed length $(\mu \mathrm{m})$

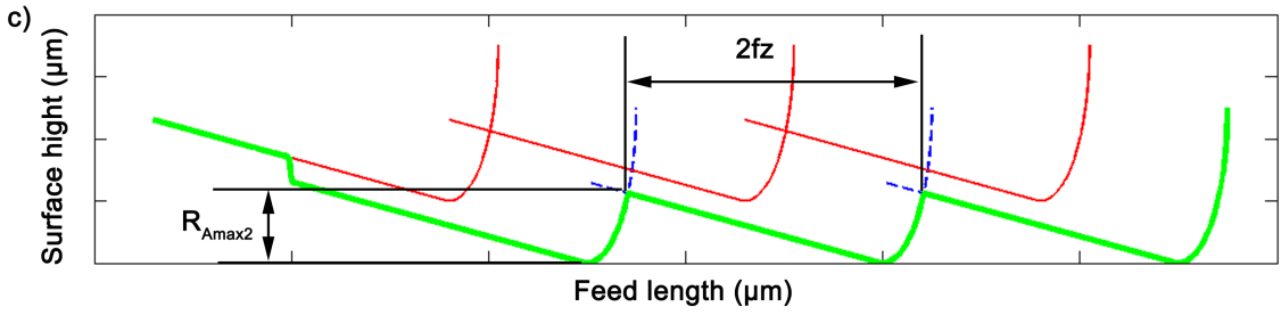

Fig.5 Schematic diagram of the machined surface. a) Ideal surface; b) Surface type 1 with axial runout; c) Surface type 2 with axial runout

Assuming that the Eq.(3) is equal to Eq.(4), the relationship between the axial runout and feed per tooth can be obtained, which could be expressed as:

$f_{c z}=2 r_{\text {axial }} / \tan \left(k_{r}^{\prime}\right)$

Therefore, when the feed per tooth $\left(f_{z}\right)$ is less than the critical feed per tooth $\left(f_{c z}\right)$ under a specific axial runout $\left(r_{\text {axial }}\right)$, the machined surface belongs to the surface of type 2 . Differently, when $f_{\mathrm{z}}$ is larger than $\left(f_{c z}\right)$, the machined surface of type 1 could be generated. According to Eq(5), an axial runout judgment diagram could be obtained, as shown in Fig.6. 
Thus, the critical axial runout could be finally determined by the transformation of surface topography from type 2 and type 1. Overall, by comparing the machined surface topographies at different feeds per tooth, the axial runout of the spindle can be predicted.

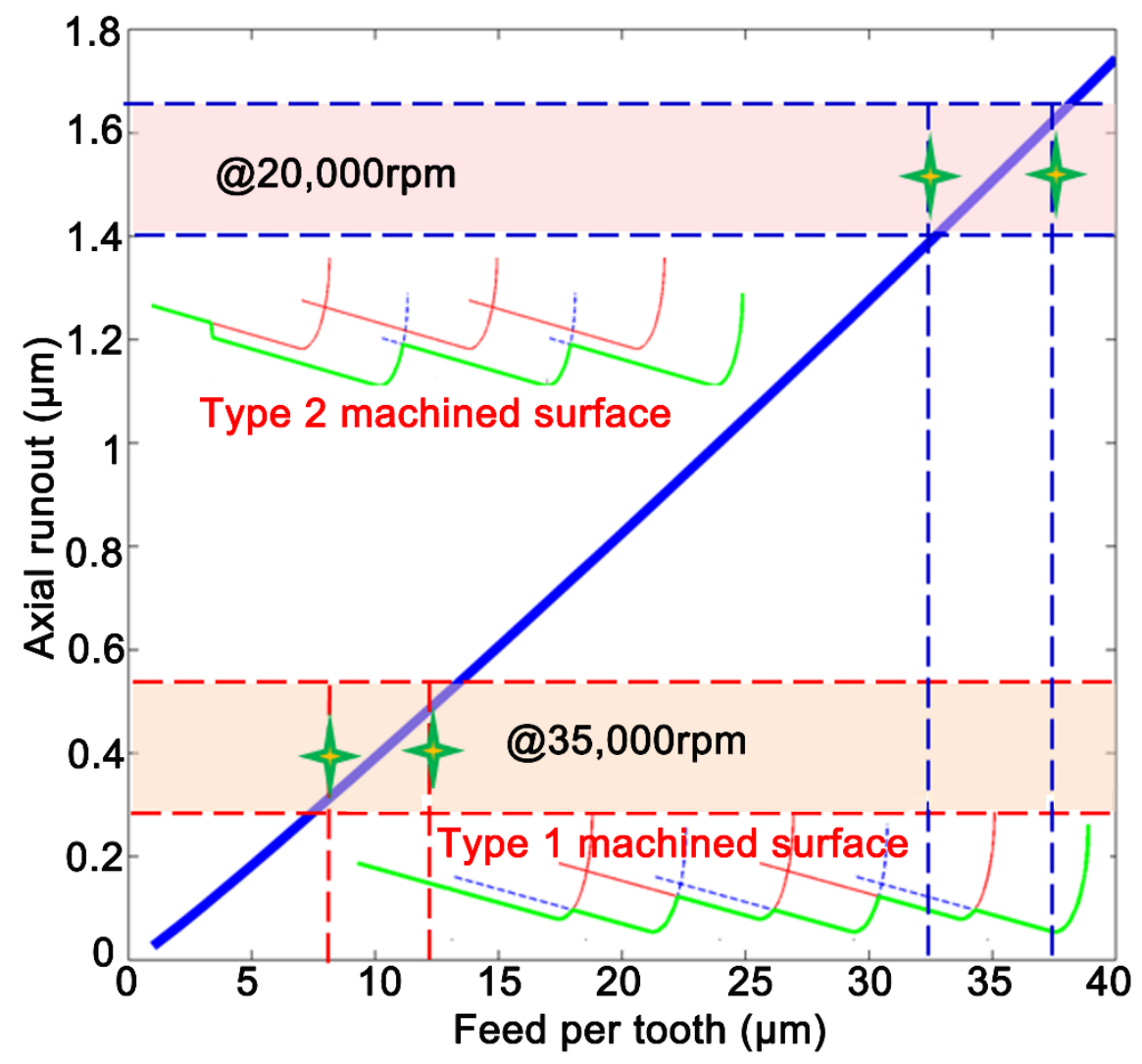

Fig.6 Axial runout judgment diagram

The procedure of the proposed axial runout detection method can be described in Fig.7. Firstly, the geometrical parameters of the cutter (flat micro end mills), including corner radius and rake angle, are measured by a scanning electron microscope (SEM). Secondly, the tool edge profile, which is described in a mathematical model, is used to predict the surface generation. Meanwhile, the effects of the machining parameters, including feed per tooth and an assumed axial runout value are considered. Then surface topography under the assumed machining conditions and the axial runout is generated by the trajectories of the cutter edge profile. Thus, the influence of the machining parameters and axial runout on the surface topography is investigated. On this basis, a judgment map used to illustrate the relationship between machining parameters or axial runout and surface topography is established. Further, the cutting experiments with different feed per tooth and a specific spindle speed are then carried out, and the machined surfaces are analyzed by improved dimensional empirical mode decomposition, with the feed per tooth increase from $f_{n-1}$ to $f_{n}$, the surface topography changes from type 2 to type 1 , and by comparing with the axial runout judgment map, the axial runout is determined. 


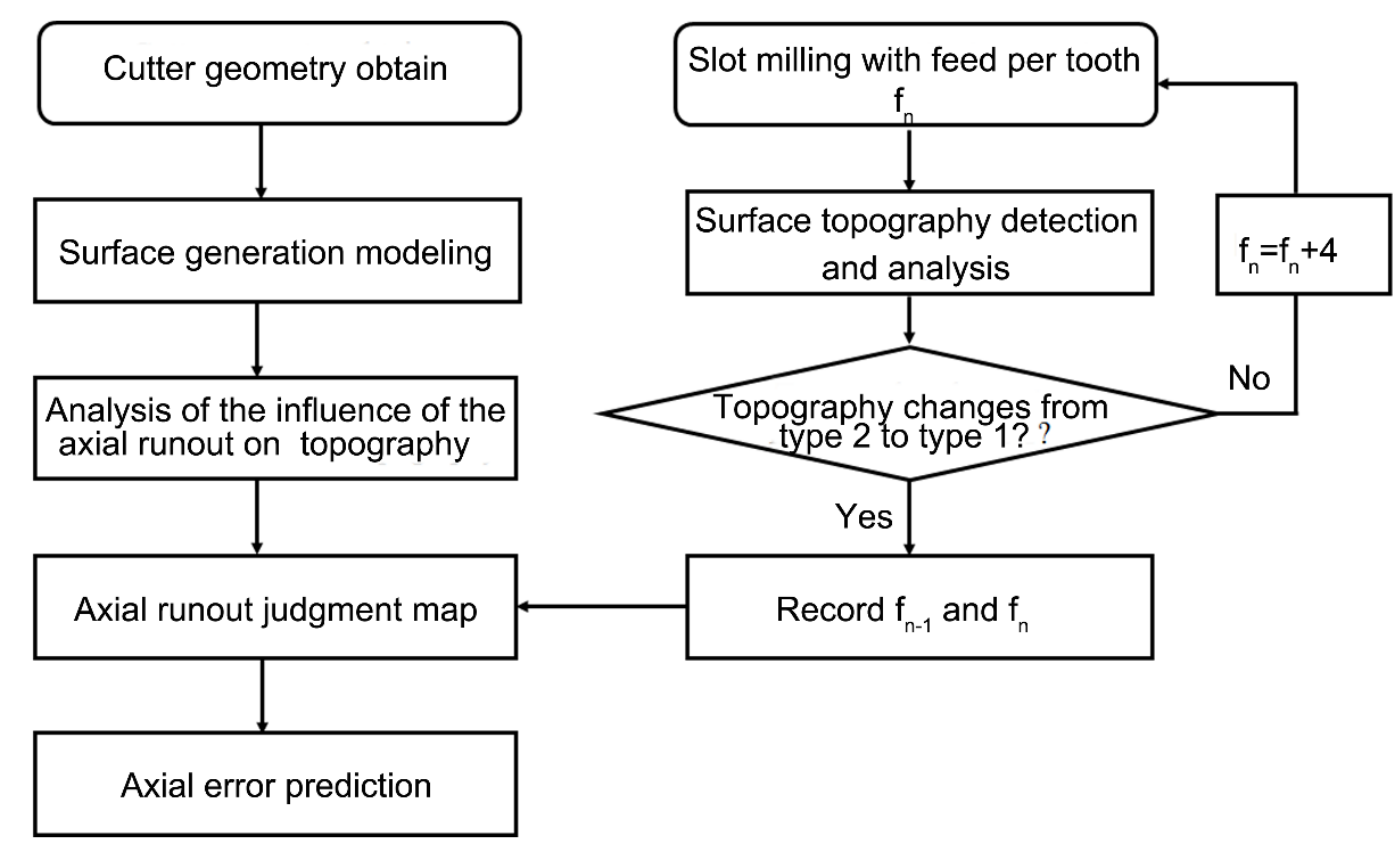

Fig.7 The flow chart of the axial runout detection process

\subsection{Experimental verification design of axial runout judgment diagram}

The machining experiments were performed on a 3-axis precision milling machine tool (Nanowave MTS5R), which is equipped with three precision linear stages and a high speed spindle. Moreover, the linear stages are mainly driven by DC servo motors with smallest feed of $0.1 \mu \mathrm{m}$, and the rotation speed of the spindle could be varied from 5,000 to $80,000 \mathrm{rpm}$. In the slot milling, two-flute micro flat end mills with a diameter of $0.5 \mathrm{~mm}$ are adopted. In order to ensure the relevance of the used data, an easy-to-machine material Al 6061 is used, and a low axial cut depth of $15 \mu \mathrm{m}$ is adopted in this study. This will avoid the effects of the self-excited vibration and rapid tool wear on the profile of the cutting marks. Therefore, during machining experiments the data of the cutter can be recognized as invariable.

In order to verify the proposed model and to reduce the test errors of capacitive sensor due to the airflow in high rotation speed, spindle rotation speeds ranging from 5000 to 80000 rpm were used in the experiments. The detailed machining parameters are given in Table 2. It can be seen that different feed per tooth are adopted in the machining experiments at same spindle rotation speed. The feed per tooth tends to increase by $4 \mu \mathrm{m}$ for each slot.

Table 2 Machining parameters

\begin{tabular}{lll}
\hline Number & Rotational speed $/ \mathrm{rpm}$ & Feed per tooth $/ \mu \mathrm{m}$ \\
\hline 1 & 5000 & $1 / 5 / 9 / 13 / 17$ \\
\hline 2 & 20000 & $2 / 6 / 10 / 14 / 18$ \\
\hline 3 & 35000 & $4 / 8 / 12 / 16 / 20$ \\
\hline 4 & 50000 & $5 / 9 / 13 / 17 / 21$ \\
\hline 5 & 65000 & $6 / 10 / 14 / 18 / 22$ \\
\hline 6 & 80000 & $7 / 11 / 15 / 19 / 23$ \\
\hline
\end{tabular}

The machined surfaces are detected by a white light interferometer surface profilometer 
(Vecco NT1100). For the initial feed per tooth $f_{z}$ which is smaller than $f_{c z}$, the type 2 of the machined surface is generated, thus, the distances of the neighboring tool marks are around twice of the feed per tooth. With the feed per tooth increase from $f_{n-1}$ to $f_{n}$, the topography of the machined surface changes from type 2 to type 1 , which means the feed per tooth is larger than $f_{c z}$, the distances of the neighboring tool marks are around the feed per tooth, as shown in Fig.8. In this way, the range of the critical feed per tooth is found, and on the basis of the axial runout judgment map described in Fig.6, the range of the axial runout can be finally obtained.

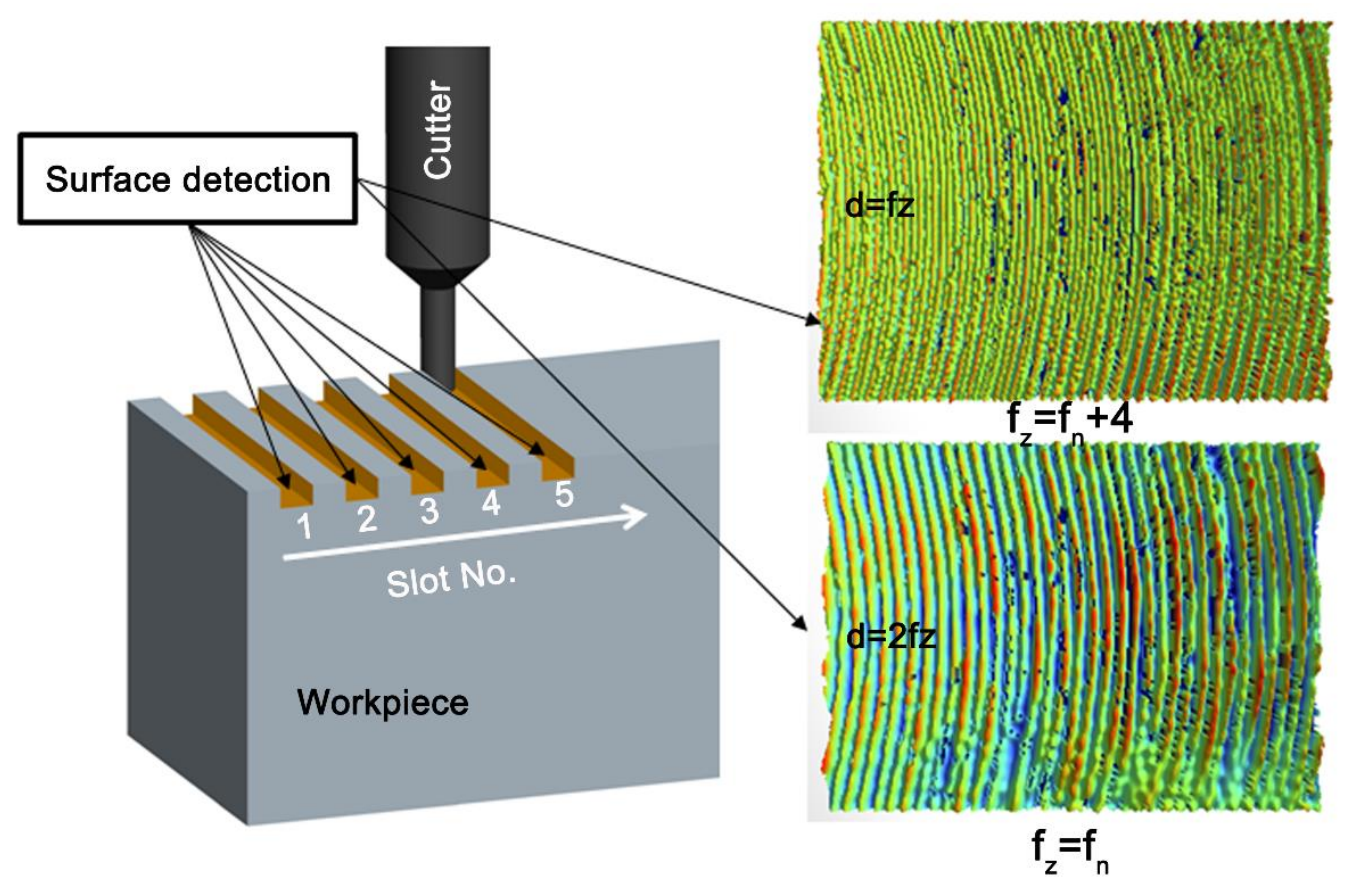

Fig.8 Prediction process of the axial runout

\section{The detection method of the machined surface}

Considering the elastic recovery of the material and the small scale of the tool marks, it is difficult to obtain the accurate frequency domain information of the machined workpiece surface. In order to analyze the machined surface, the bidimensional empirical mode decomposition (BEMD) method is applied.

\subsection{Bidimensional empirical mode decomposition method}

BEMD, which is developed by Huang [17], is a data driven method using the envelope analysis based sifting process, which does not require prior knowledge for the decomposition process. The original signal can be represented with oscillation modes imbedded in the signal, which were regarded as intrinsic mode functions(IMFs). The advantages of BEMD method applied to analyze nonlinear data have been verified by many applications [18-20]. Assuming a two dimensional signal $s(x, y)$, the BEMD method was performed as follows to extract IMFs in the signal:

Step 1. Initialization, set $R_{0}(x, y)=s(x, y)$, and define $j=1$ as the index of the two dimensional IMFs.

Step 2. Implement the envelope analysis process, and obtain the $j^{\text {th }} \mathrm{IMF}$. 
1) Define temporary signal $H_{k-1}(x, y)=R_{j}(x, y)$, and set iteration number $k=1$.

2) Identify all the maxima from the two dimensional signal $H_{k-1}(x, y)$, and obtain the upper envelope $U_{k-1}(x, y)$ with the spline interpolation.

3) Identify all the minima of $H_{k-1}(x, y)$, and obtain the lower envelope $L_{k-1}(x, y)$ by the spline fitting process.

4) Calculate the mean value surface, $M_{k-1}(x, y)=\left(U_{k-1}(x, y)+L_{k-1}(x, y)\right) / 2$.

5) Obtain new temporary signal $H_{k}(x, y)$ by subtracting the mean value surface from the temporary signal, $H_{k}(x, y)=H_{k-1}(x, y)-M_{k-1}(x, y)$, and $H_{k}(x, y)$ was regarded as a pseudo mode.

6) Repeat 2) - 5) with $k$ times iteration, get an intrinsic mode function $c_{j}(x, y)$ when pseudo mode satisfying the definition of a standard IMF.

7) $\operatorname{Substract} c_{j}(x, y)$ from the original signal $R_{j+1}(x, y)=R_{j}(x, y)-c_{j}(x, y)$

Step 3. Update indicator $j$, and repeat step 2. Stop the iterative process until satisfying stopping criterion. Then,the original signal $s(x, y)$ can be decomposed into a series of IMFs and a residual signal,

$$
s(x, y)=\sum_{i=1}^{j} c_{j}(x, y)+\operatorname{res}(x, y)
$$

Where, $j$ is the number of decomposed IMFs and $\operatorname{res}(x, y)$ is a remained signal.

For the definition of a standard IMF, it was regarded on two aspects: (1) the number of extrema must be less than or equal to the number of zero crossings. (2) the value of any point in the average surface obtained by the upper envelope and the lower envelope was zero. The sifting process will be stopped when the residue is smaller than a predetermined value, or no more IMFs can be extracted from the residue signal. By above sifting process, the original two-dimensional signals finally consist of the $j$-empirical sub-surfaces with spatial frequencies, and a residual sub-surface denoting the signal tendency.

\subsection{Data analysis and discussion}

In this section, taking the machined surface results of Set 3(spindle speed is $35,000 \mathrm{rpm}$ ) as an example, the runout and surface detection method proposed in this study is proposed. Fig. 9 shows the BEMD analysis results for machined surface obtained at the feed per tooth of $8 \mu \mathrm{m}$. It can be seen that the original signal exhibits periodical cutting paths. By BEMD method, the original signal of the machined surface was decomposed into four IMFs and a residue signal. As given in IMF2, a periodic feature with a spacing of $0.0154 \mathrm{~mm}$ could be clearly found. It corresponds to the spatial frequency of $64.94 \mathrm{~mm}^{-1}$, which is illustrated in the PSD analysis results of Fig.10. One can note that the spacing of $0.0154 \mathrm{~mm}(15.4 \mu \mathrm{m})$ of the periodic feature shown in IMF2 is nearly twice of the feed per tooth of $8 \mu \mathrm{m}$. That is to say, the feed per tooth is smaller than the critical feed per tooth. Therefore, the machined surface belongs to the type 2. The surface topography of the machined surface consists of the tool marks formed by only one tooth. As for the tool marks of another tooth, owing to the existence of the tool axial 
runout, they have been removed.
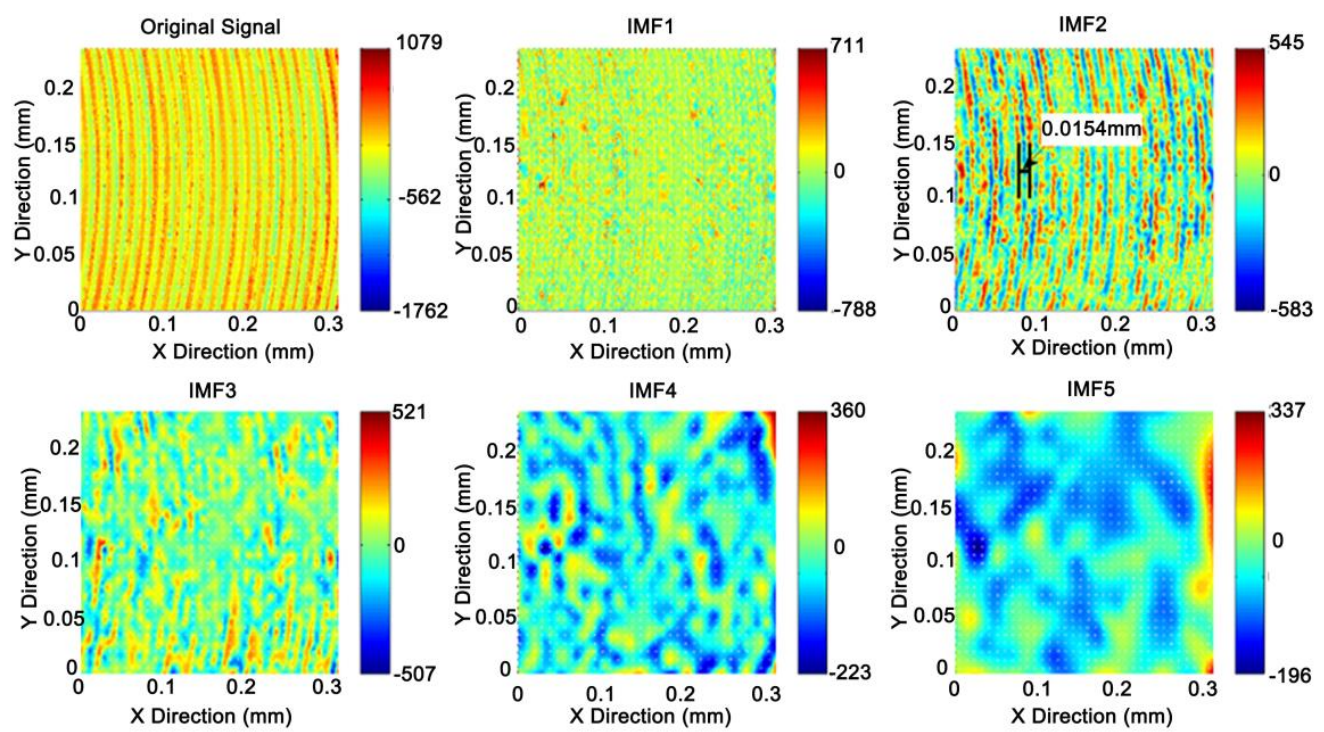

Fig.9 Machined surface data decomposed by BEMD method (feed per tooth: $8 \mu \mathrm{m}$, spindle speed: $35,000 \mathrm{rpm})$

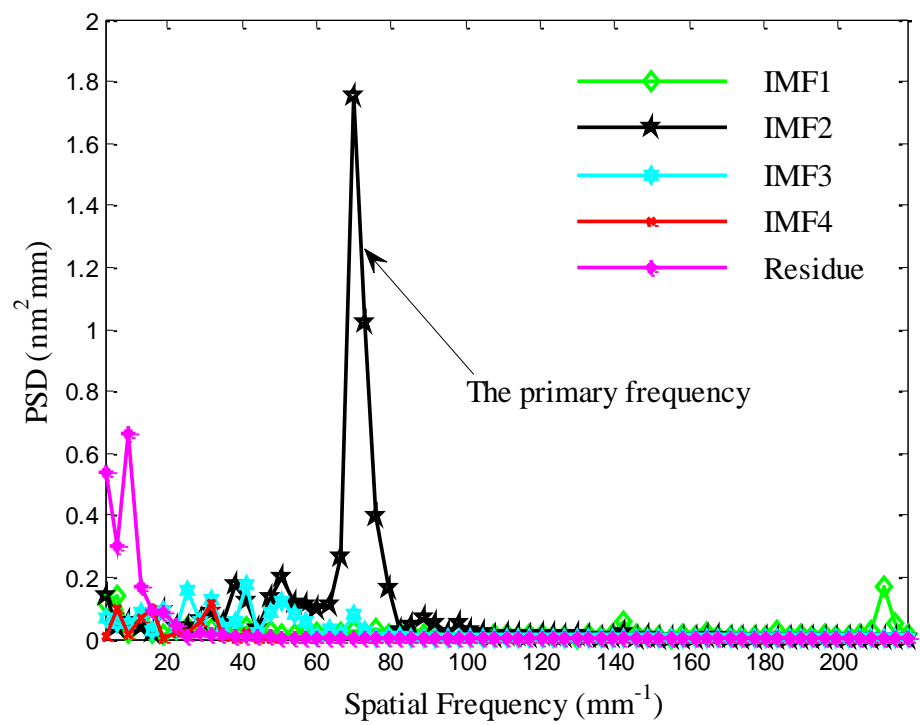

Fig.10 PSD analysis of IMFs (feed per tooth: $8 \mu \mathrm{m}$, spindle speed: 35,000rpm)

Fig.11 shows the BEMD analysis results for the machined surface at the feed per tooth of 12 $\mu \mathrm{m}$. From the original signal, the periodical features that represent tool marks could be also clearly seen, which is similar to those shown in Fig.9. Further, the original signal is decomposed into five sub-surfaces. IMF1 has the highest frequency, and it is regarded as noise or interference during the machining process. From IMF2 and IMF3, two periodic features mixed in the original signal could be identified. In IMF2, the periodic length of the tool marks is $0.0122 \mathrm{~mm}(12.2 \mu \mathrm{m})$. In IMF3, differently, the periodic length of the decomposed sub-surface is $0.0244 \mathrm{~mm}(24.4 \mu \mathrm{m})$, which is twice of that obtained in IMF2. 
Also, it can be seen that the amplitude of the several periodic features in IMF4 is lower. The residual signal was regarded as the tendency of original surface.

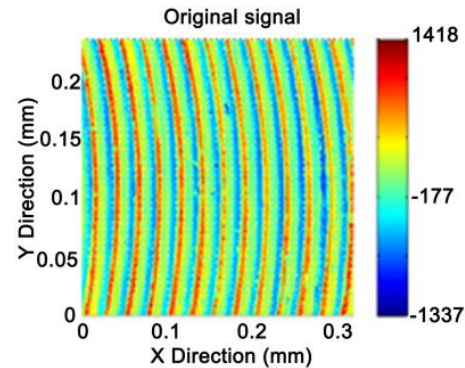

IMF3

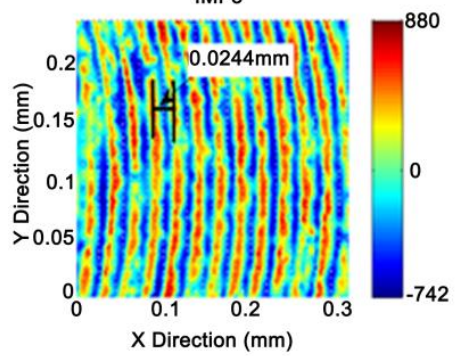

IMF1

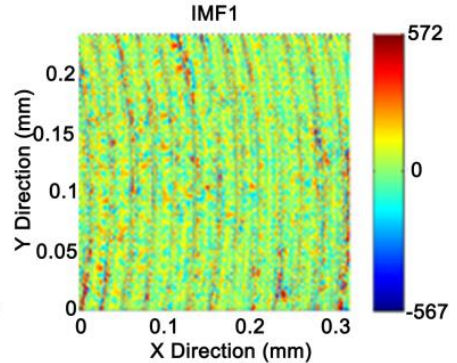

IMF4

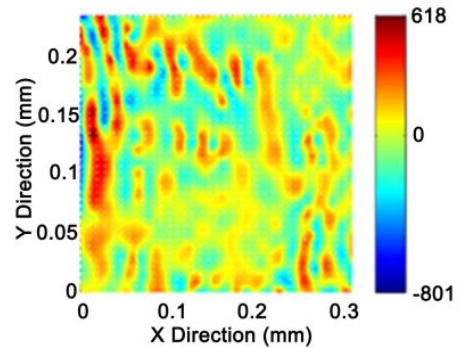

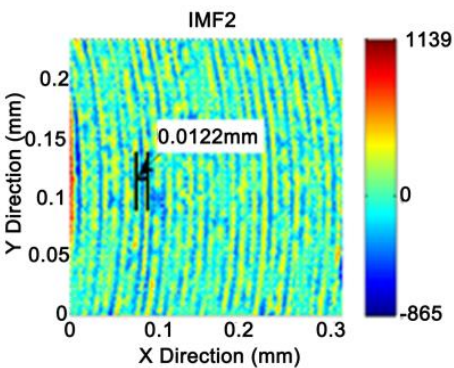

IMF5

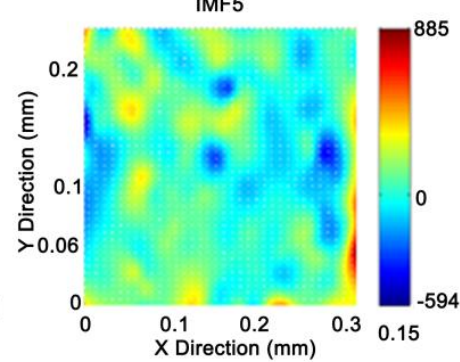

Fig.11 Machined surface decomposed by BEMD method (feed per tooth: $12 \mu \mathrm{m}$, spindle speed:

$$
35,000 \mathrm{rpm})
$$

The PSD analysis of IMFs is shown in Fig. 12, it can be seen that the $1^{\text {st }}$ primary frequency in IMF3 is $41.04 \mathrm{~mm}^{-1}$, which corresponds to the periodic feature with spacing of $0.0244 \mathrm{~mm}$ in Figure 12 . The $2^{\text {nd }}$ primary frequency is $82.07 \mathrm{~mm}^{-1}$, consistent with the periodic feature with spacing of $0.0122 \mathrm{~mm}$ in IMF2(see Figure 11). Also, part of periodic features exhibited in IMF4 could be seen. Meanwhile, the spatial frequencies and amplitudes of the residual signals are lower and smaller, respectively. Overall, the spacing $0.0122 \mathrm{~mm}$ of $2^{\text {nd }}$ periodic features is close to the feed per tooth of $12 \mu \mathrm{m}$, while the spacing $0.0244 \mathrm{~mm}$ of the $1^{\text {st }}$ periodic features is nearly twice of the feed per tooth of $12 \mu \mathrm{m}$. Hence, the machined surface belongs to the type 1 . The surface topography of the machined surface is generated by the tool marks of both teeth, which indict the feed per tooth is larger than the critical feed per tooth. 


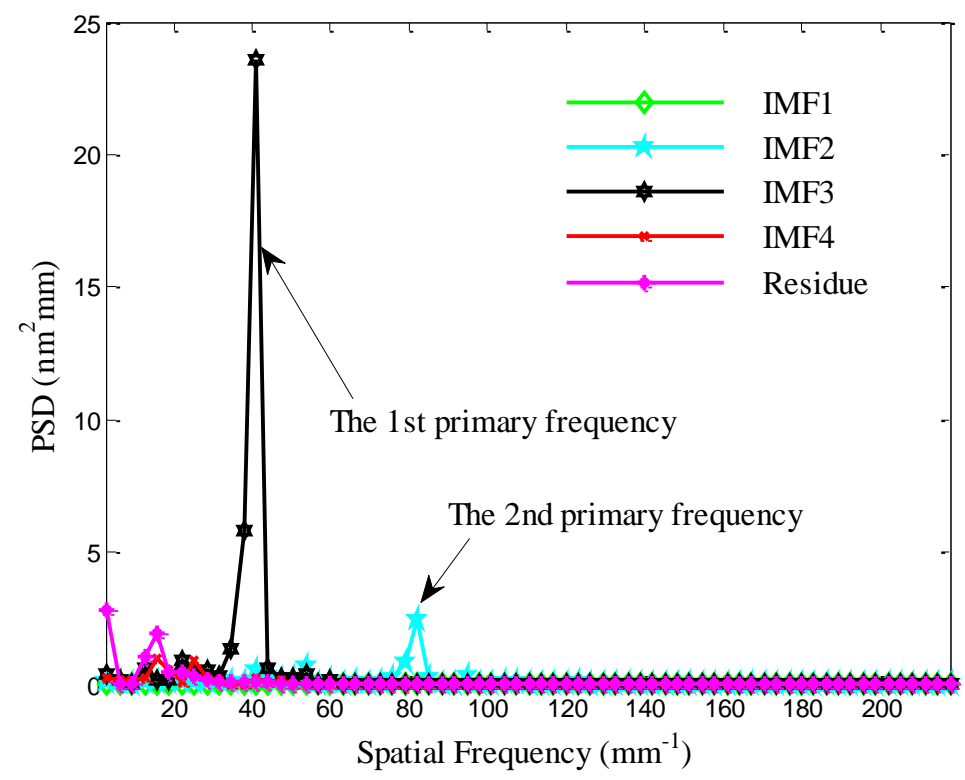

Fig.12. PSD analysis of IMFs (Feeding parameter larger than threshold)

As for other three IMFs and the residual signal, no evident periodic features could be identified from both of the sub-surfaces and the corresponding PSD curves. From the PSD analysis results of IMFs demonstrated in Fig.10 and Fig.12, it can be clearly observed that two and one primary spatial frequencies are respectively exhibited in Fig.12 and Fig.10. The difference in the peak numbers of primary spatial frequencies clearly indicates that the feed rates greatly affect the generation of the surface topography of machined surfaces. In addition, the radial runout of the precision high speed spindle is usually less than $1 \mu \mathrm{m}$, in the test the feed per tooth is larger than $1 \mu \mathrm{m}$, thus the influence of the radial runout and the minimum cutting chip thickness on the surface topography can be neglected.

Finally, according to the judgment map shown in Fig.6, the tool axial runout at the speed of $35,000 \mathrm{rpm}$ is between $0.3 \sim 0.5 \mu \mathrm{m}$ (two examples discussed in this section are marked in Fig.6).

\section{Results analysis and Experimental verification}

Using the above method, the cutter axial runout obtained in the experiments of each set as summarized in Table 3.

Table 3 Cutter axial errors

\begin{tabular}{ccc}
\hline Set No. & Predicted axial runout $/ \mu \mathrm{m}$ & Measured runout $/ \mu \mathrm{m}$ \\
\hline 1 & $<0.1$ & 0.08 \\
\hline 2 & $1.4 \sim 1.7$ & 1.2 \\
\hline 3 & $0.3 \sim 0.5$ & 0.5 \\
\hline 4 & $0.8 \sim 1.1$ & 0.8 \\
\hline 5 & $1.0 \sim 1.3$ & 1.1 \\
\hline 6 & $1.3 \sim 1.5$ & 1.5 \\
\hline
\end{tabular}


To verify the feasibility of above novel method for measuring spindle runout, the axial runout of the high speed spindle used in the machining experiment was experimentally and directly measured by using a modular capacitive sensor system (Micro-epsilon, capaNCDT 6200), a capacitive sensor (Micro-epsilon, CS005) with a resolution of $1 \mathrm{~nm}$ and the measuring range of $50 \mu \mathrm{m}$. As shown in Fig.13 a) and b), a precision runout pin was mounted on the spindle, and the displacement measurement was conducted. In the milling experiments of set1, owing to the low rotation speed, the axial runout of the cutter is very small. Thus, the second surface type is hard to occur, in spite of the very small feed per tooth. The value of the axial runout determined by the proposed measurement method is less than $0.1 \mu \mathrm{m}$. Similarly, that obtained from direct measurement experiments is $0.08 \mu \mathrm{m}$, agreeing well with the predicted value $(<0.1 \mu \mathrm{m})$.

Table 3 lists the predicted and tested results of six sets at different spindle rotation speeds. It can be found that the axial runout of the cutter increases with the rotational speed. But that obtained from experiments of Set 2 is the largest. It should be ascribed to the approximate equivalent spindle rotation frequency and dominant vibration frequency of the machine system. It leads to the occurrence of the resonance response, thereby introducing a significant peak. Overall, the predicted results are consistent with the experimentally measured axial runout, clearly validating the effectiveness of the proposed method.
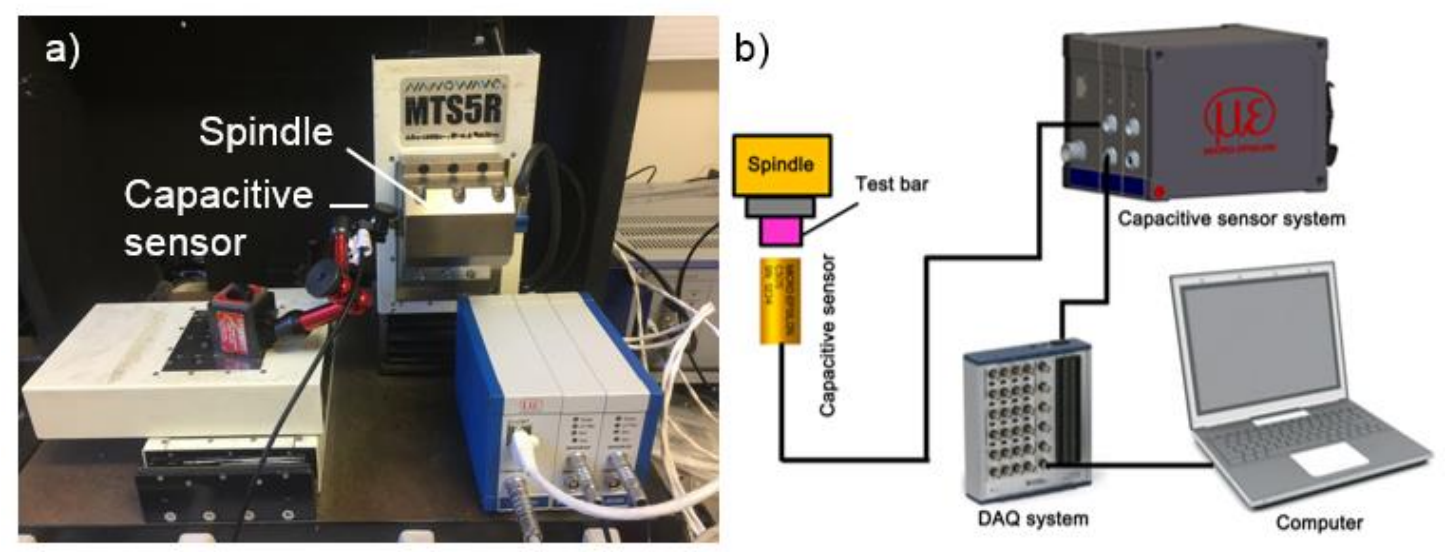

Fig.13 Axial runout test setup. a) Experiment setup, b) Schematic setup

\section{Conclusion}

In this paper, a novel method to quantify the axial runout of high speed spindle based on the tool marks of milling machined surface is proposed. A numerical model to describe the relationship between axial tool runout and tool marks on the machined surface is established, laying the foundation for the determination of axial runout by combing with milling experiments. Moreover, serials of micro milling experiments are performed to verify the values of tool runout obtained by the proposed novel method. The following conclusions can be drawn:

1. The axial runout of the cutter has significant influence on the surface topography generation. A numerical analysis method based on the relationship between axial runout and surface topography is established, and it can be used to predict the tool axial runout at a 
specific spindle rotation speed.

2.The bidimensional empirical mode decomposition method is applied to analyze the tool marks on the machined surface. On this basis, by further combining with the axial runout judgment map, the axial runout is finally determined.

3.The proposed method is an effective tool to determine the actual running accuracy of the cutter at different operating speeds, avoiding the application of a dedicated spindle error measurement equipment.

\section{Acknowledgments}

The authors gratefully acknowledge financial support of the National Natural Science Foundation of China (Grant No.51505107), Project (HIT.NSRIF.2017029) supported by Natural Scientific Research Innovation Foundation in Harbin Institute of Technology and the Engineering and Physical Sciences Research Council (EP/M020657/1).

\section{Conflict of interest}

The authors declare that there is no conflict of interest.

\section{Reference}

[1] Chen, D., Fan, J., and Zhang, F., 2012, "An identification method for spindle rotation error of a diamond turning machine based on the wavelet transform," The International Journal of Advanced Manufacturing Technology, 63(5-8, pp. 457-464.

[2] Zhang, G. X., and Wang, R. K., 1993, "Four-point method of roundness and spindle error measurements," CIRP Annals-Manufacturing Technology, 42(1), pp. 593-596.

[3] Martin, D. L., Tabenkin, A. N., and Parsons, F. G., 1995, "Precision spindle and bearing error analysis," International Journal of Machine Tools and Manufacture, 35(2), pp. 187-193.

[4] Grejda, R., Marsh, E., and Vallance, R., 2005, "Techniques for calibrating spindles with nanometer error motion," Precision Engineering, 29(1), pp. 113-123.

[5] Chen, Ni,, Chen, M. J., Wu, C. Y., Pei, X. D., Qian, J., and Reynaerts, D., 2017, "Research in minimum undeformed chip thickness and size effect in micro end-milling of potassium dihydrogen phosphate crystal," International Journal of Mechanical Sciences 134,pp. 387-398.

[6] Schmitz, T. L., Couey, J., Eric, M., Mauntler, N., Hughes, D., "Runout effects in milling: surface finish, surface location error, and stability." International Journal of Machine Tools and Manufacture 47(5), pp. 841-851.

[7] Chen, W. Q., Huo, D. H., Teng, X. Y., and Sun, Y. Z, "Surface Generation Modelling for Micro end Milling Considering the Minimum Chip Thickness and Tool Runout," Procedia CIRP, 58, pp. 364-369.

[8] Kanl1 M. Modeling of cutting forces in micro milling including run-out [D]. Bilkent University, 2014.

[9] Zhang, X., Ehmann, K. F., Yu, T., and Wang, W., 2016, "Cutting forces in micro-end-milling processes," International Journal of Machine Tools and Manufacture, 107, pp. 21-40. 
[10] Lee, C.,, Zhao, R. and Jeon, S., 2017, "A simple optical system for miniature spindle runout monitoring," Measurement, 102, pp. 42-46.

[11] Nakkiew, W., Lin, C. W., and Tu, J. F., 2006, "A new method to quantify radial error of a motorized end-milling cutter system at very high speed rotations," International Journal of Machine Tools and Manufacture, 46(7), pp. 877-889.

[12] Krüger, M., and Denkena, B,. 2013, "Model-based identification of tool runout in end milling and estimation of surface roughness from measured cutting forces," The International Journal of Advanced Manufacturing Technology, 65(5-8), pp.1067-1080.

[13] Seethaler, R. J., and Yellowley, I., 1999, "The identification of radial runout in milling operations," Journal of manufacturing science and engineering, 121(3), pp. 524-531.

[14] Jing, X., Tian, Y., Yuan, Y., and Wang, F., 2017, "A runout measuring method using modeling and simulation cutting force in micro end-milling," The International Journal of Advanced Manufacturing Technology, 91(9-12), pp. 4191-4201.

[15] Bissacco, G., Hans, N. H., and Slunsky J..2008, "Modelling the cutting edge radius size effect for force prediction in micro milling," CIRP Annals-Manufacturing Technology, 57(1), pp.113-116.

[16] Li, H., and Wu., 2016, "Development of a hybrid cutting force model for micromilling of brass," International Journal of Mechanical Sciences, 115, pp.586-595.

[17] Vogler, M. P., Shiv G. K., and Richard E. D., 2004, "On the modeling and analysis of machining performance in micro-endmilling, Part II: Cutting force prediction," Journal of manufacturing science and engineering 126(4), pp. 695-705.

[18] Norden, E. H., Zheng, S., Steven, R. L. 1971, "The empirical mode decomposition and the Hilbert spectrum for nonlinear and non-stationary time series analysis," in Proceedings of the Royal Society of London A: mathematical, physical and engineering sciences. 454.

[19] Zhang, B., Zhang, C., Wu, J, 2014, "A medical image fusion method based on energy classification of BEMD components," Optik - International Journal for Light and Electron Optics, 125(1), pp. 146-153.

[20] Acharya, U. R., Mookiah, M. R. K., Koh, J., E., W., 2016, "Automated screening system for retinal health using bi-dimensional empirical mode decomposition and integrated index," Computers in Biology and Medicine, 75, pp. 54-62. 